\title{
The effect of youth assertive community treatment: a systematic PRISMA review
}

\author{
Richard Vijverberg ${ }^{1,2,3^{*}}$, Robert Ferdinand ${ }^{1}$, Aartjan Beekman ${ }^{2,3}$ and Berno van Meijel ${ }^{3,4,5}$
}

\begin{abstract}
Background: During the past decades deinstitutionalisation policies have led to a transition from inpatient towards community mental health care. Many European countries implement Assertive Community Treatment (ACT) as an alternative for inpatient care for "difficult to reach" children and adolescents with severe mental illness. ACT is a well-organized low-threshold treatment modality; patients are actively approached in their own environment, and efforts are undertaken to strengthen the patient's motivation for treatment. The assumption is that ACT may help to avoid psychiatric hospital admissions, enhance cost-effectiveness, stimulate social participation and support, and reduce stigma.

ACT has been extensively investigated in adults with severe mental illness and various reviews support its effectiveness in this patient group. However, to date there is no review available regarding the effectiveness of youth-ACT. It is unknown whether youth-ACT is as effective as it is in adults. This review aims to assess the effects of youth-ACT on severity of psychiatric symptoms, general functioning, and psychiatric hospital admissions.
\end{abstract}

Method: A systematic literature search was conducted in PubMed, Cochrane Library, PsychINFO and CINAHL published up to March 2017. To assess methodological quality of the included studies, the Oxford Centre of Evidence-Based Medicine grading system was used.

Results: Thirteen studies were included in this review. There are indications that youth-ACT is effective in reducing severity of psychiatric symptoms, improving general functioning, and reducing duration and frequency of psychiatric hospital admissions.

Conclusions: The current literature on youth-ACT is limited but promising. There are indications that youth-ACT is effective in reducing severity of psychiatric symptoms, improving general functioning, and reducing duration and frequency of psychiatric hospital admissions. The effect of youth-ACT may be comparable with the effect of ACT in adults. Similar as in adult ACT, the studies on youth-ACT found effects that vary from small to large. Randomized experimental research designs are needed to further corroborate effectiveness.

Keywords: Assertive community treatment, Assertive outreach, Adolescent, Review

\section{Background}

In many countries, over the past decades, a transition has taken place from inpatient to community mental health care for individuals with a severe mental illness. Assertive Community Treatment (ACT) can be considered the result of this transition [1-3].

ACT [4], the most thoroughly studied type of psychiatric case management in adults [5], is characterized by 9

\footnotetext{
* Correspondence: r.vijverberg@ggz-delfland.nl

'Department of Child and Adolescent Psychiatry, GGZ-Delfland, PO-box 5016, 2600, GA, Delft, The Netherlands

${ }^{2}$ VU Medical Centre/GGZ-InGeest, Amsterdam, The Netherlands

Full list of author information is available at the end of the article
}

core elements [6-8]: (a) home-based treatment (obligatory), (b) small caseload (size < 10), (c) patients difficult to reach, (d) transition (from clinic to home) case management, (e) early intervention, (f) psychiatric assessment in the community, (g) family support, (h) reintegration/vocational and educational therapy, (i) pharmacology. ACT teams share responsibility for patients. ACT is characterized by an active team approach which focusses on establishing a solid therapeutic alliance between patients, their relatives, and professionals. Also, efforts are undertaken to strengthen a patient's motivation for treatment and care [9]. 
The World Health Organization (WHO) Europe has declared assertive outreach care a necessary alternative for inpatient care. This is because treatment focuses on strengthening the patient's autonomy by enhancing skills and coping, but also by collaboration with relatives and the broader social network. Even during inpatient treatment, the ACT case manager remains involved, which enhances continuity of care [10]. In Europe, 22 out of 42 countries have policies and/or legislation requiring that individuals with severe mental disorders have access to Assertive Community Treatment or assertive outreach related services [10].

Compared to adults, children and adolescents with severe mental illness are at higher risk of being hospitalized [11-14]. Severe mental illness can be defined as a mental, behavioral, or emotional disorder, that meets the Diagnostic and Statistical Manual of Mental Disorders (DSM) criteria, and which results in serious functional impairment substantially interfering with major life activities [15]. The National Institute for health and Care Excellence (NICE) recommends assertive outreach services for children and adolescents with several severe mental illnesses (see guidelines "Psychosis and schizophrenia in children and young people" [14] and "Bipolar disorder, in adults, children and young people in primary and secondary care" [16]). Horatio, the European Association for Psychiatric Nurses [17], and the Executive Agency for Health and Consumers [18] also recommend ACT services for youths.

Because the implementation of youth-ACT is increasing, it is crucial to evaluate its benefits. ACT has been extensively investigated in adults and various reviews have published positive effects on reducing psychiatric symptoms, improving general functioning and reducing hospitalizations [19-30]. However, to date a systematic review regarding the effectiveness of youth-ACT is not available. It is unknown whether youth-ACT is effective as it is in adults [31].

The aim of the current review is to assess the effects of youth-ACT in three areas: severity of psychiatric symptoms, general functioning, and frequency and duration of psychiatric hospital admissions, since ACT has been primarily developed to positively influence these three outcomes [4].

\section{Methods}

A systematic literature review in compliance with the Preferred Reporting Items for Systematic Reviews and Meta-analyses (PRISMA) guidelines [32] was conducted between August 2016 and March 2017.

\section{Inclusion criteria}

This review included English language papers that focus on patients (a) between 6 to 18 years, (b) who suffer from severe mental illness (mood disorders, behavior disorders, psychotic disorders, and/or substance use disorders), and (c) who are poorly engaged with community mental health services. A treatment program was considered as youth-ACT if it contained at least 6 out of 9 core elements [6-8] and provided information about at least one of the following three possible outcomes of youth-ACT: (a) severity of psychiatric symptoms - defined as the severity of emotional problems, behavior problems, psychotic symptoms, or addiction problems [33]; (b) general functioning - defined in the included manuscripts as general functioning, or level of school attendance, functioning in interpersonal relations and pro-social activities [34]. These constructs are important factors in general functioning and are crucial for the development of the child [35]; (c) psychiatric hospital admission - defined as referral to a psychiatric inpatient health care facility where psychiatric patients reside overnight [36].

\section{Assessment instruments}

Psychiatric symptoms, general functioning, and frequency and duration of psychiatric hospital admissions can be measured from different perspectives [37]. Assessment instruments were classified as follows: clinician-based instruments (clinical judgements by caregivers), client-based instruments (based on opinion of patients or parents), or biometric instruments (measuring biophysical values).

\section{Literature search}

A systematic literature search was conducted in PubMed, Cochrane Library, PsychINFO and CINAHL, in close collaboration with an experienced librarian. In March 2017, the following search string was applied in PubMed:

((Assertive Community Treatment[Title/Abstract] OR Assertive outreach[Title/Abstract] OR ("Community Mental Health Services"[Mesh]) AND (Act OR assertive OR outreach"[Title/Abstract]))) AND ((("Child"[Mesh] OR child"[tiab] OR "Minors"[Mesh] OR "minors"[tiab] OR "Puberty"[Mesh] OR "puberty"[tiab] OR "Pediatrics"[Mesh] OR paediatric*[tiab] OR pediatric"[tiab] OR "Adolescent"[Mesh] OR adolescen"[tiab] OR preschool*[tiab] OR "teenager" [tiab] OR "teenagers"[tiab] OR "teen"[tiab] OR "teens"[tiab] OR youth"[tiab] OR "girlhood"[tiab] OR "girl"[tiab] OR "girls"[tiab] OR "boyhood"[tiab] OR "boy"[tiab] OR "boys"[tiab] OR "school age"[tiab] OR "school-aged"[tiab] OR schoolchild"[tiab] OR "kid"[tiab] OR "kids" [tiab] OR underage"[tiab] OR juvenile"[tiab]))).

The full search strategies of the other databases are available in an Additional file 1.

\section{Selection procedure}

Figure 1 shows the selection procedure. English language papers focusing on the effectiveness of youth-ACT, without restrictions concerning research design, were 


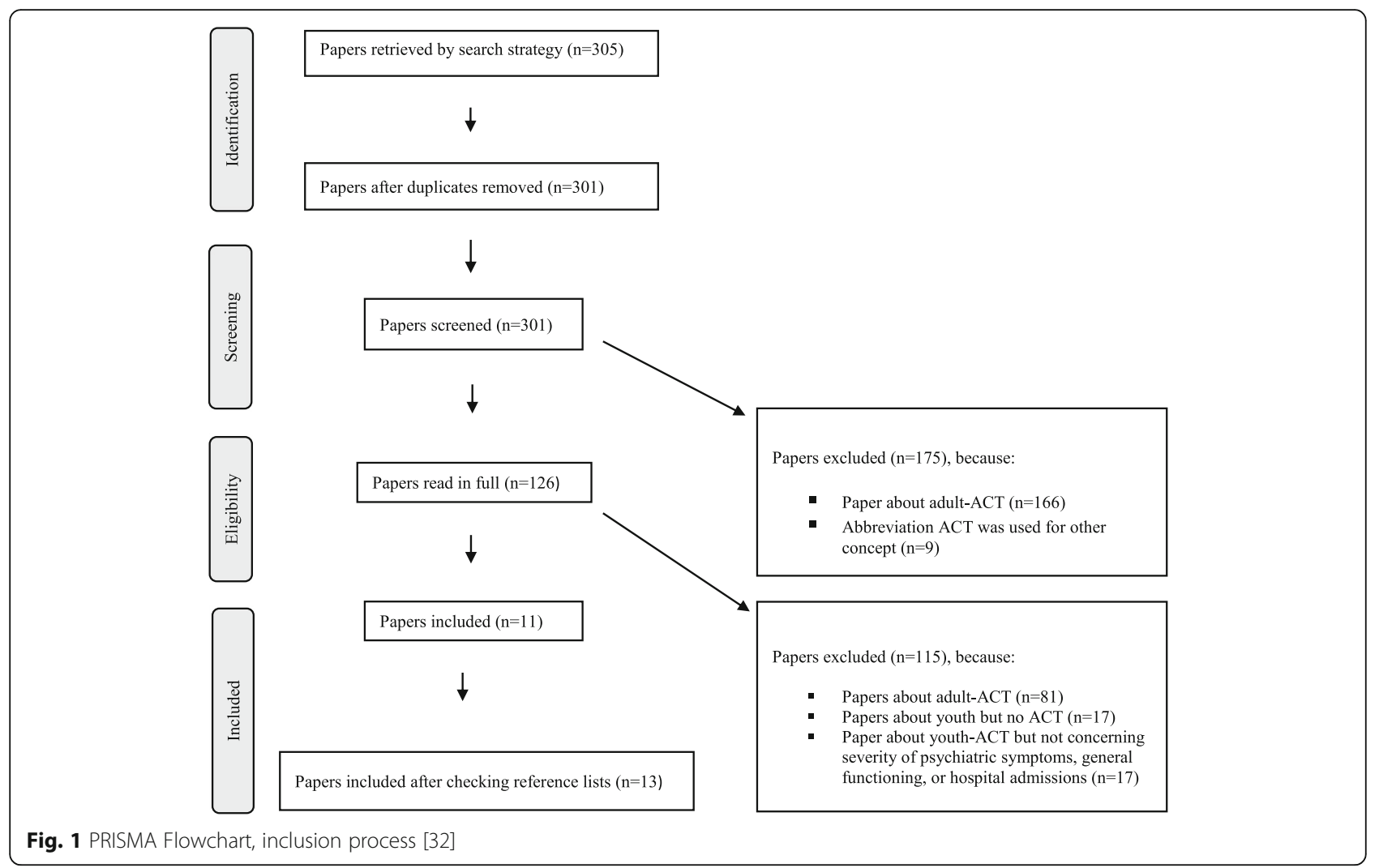

considered for inclusion. After removal of duplicates, papers were independently screened by title and abstract by two authors (RV, RF). To verify papers selected, reference lists of included papers were checked for relevant publications. Disagreements between the reviewers were resolved through discussion. This occurred in 6\% of the abstracts. All disagreements related to the decision whether the inclusion criteria were applicable. For example, the abstract did not mention the age category of the included patients. In these cases, the full text of a manuscript was read by RV, after which follow-up discussion took place with RF, until consensus was reached. Papers providing information on the effects of youth-ACT on severity of psychiatric symptoms, general functioning, or frequency and duration of psychiatric hospital admissions were included.

\section{Data extraction}

Data extraction was conducted by the first author (RV), and checked by the second author (RF). Data were extracted using a form containing the following items: author, country of origin, study design, inclusion/exclusion criteria, aim, time-period in which the study was conducted, setting of the study, patient characteristics, sample size, content of the ACT-program, duration or frequency of interventions, assessment instruments, outcomes, and conclusions. As a result, an overview was created that facilitated comparison of study designs and results.

\section{Quality appraisal}

The Oxford Centre of Evidence-Based Medicine grading system was used to assess methodological quality of the individual studies by a standardized approach [38]. The quality of studies was assessed to determine the strength of the scientific evidence of the outcomes of the different studies. The Oxford Centre of Evidence Based Medicine grading system was used because it is a widely adopted systematic hierarchy of the quality of medical research evidence. Quality was classified according to the level of evidence [38]. Studies were classified as follows. High level of evidence: 1a (=systematic review of randomized controlled trials (RCTs)), 1b (=individual RCT), 1c (=all or none RCT). Moderate level of evidence: $2 \mathrm{a}$ (=systematic review of cohort studies), $2 \mathrm{~b}$ (=cohort study or low quality RCT), 2c (=outcome research or ecological studies), 3a (=systematic review of case-control studies), 3b (=case-control study). Low level of evidence: 4 (=case series). Very low level of evidence: 5 (=expert opinion) (Table 1 ).

\section{Clinical relevance}

Although a study can be classified with a high level of evidence, statistically significant effects can still be small, 


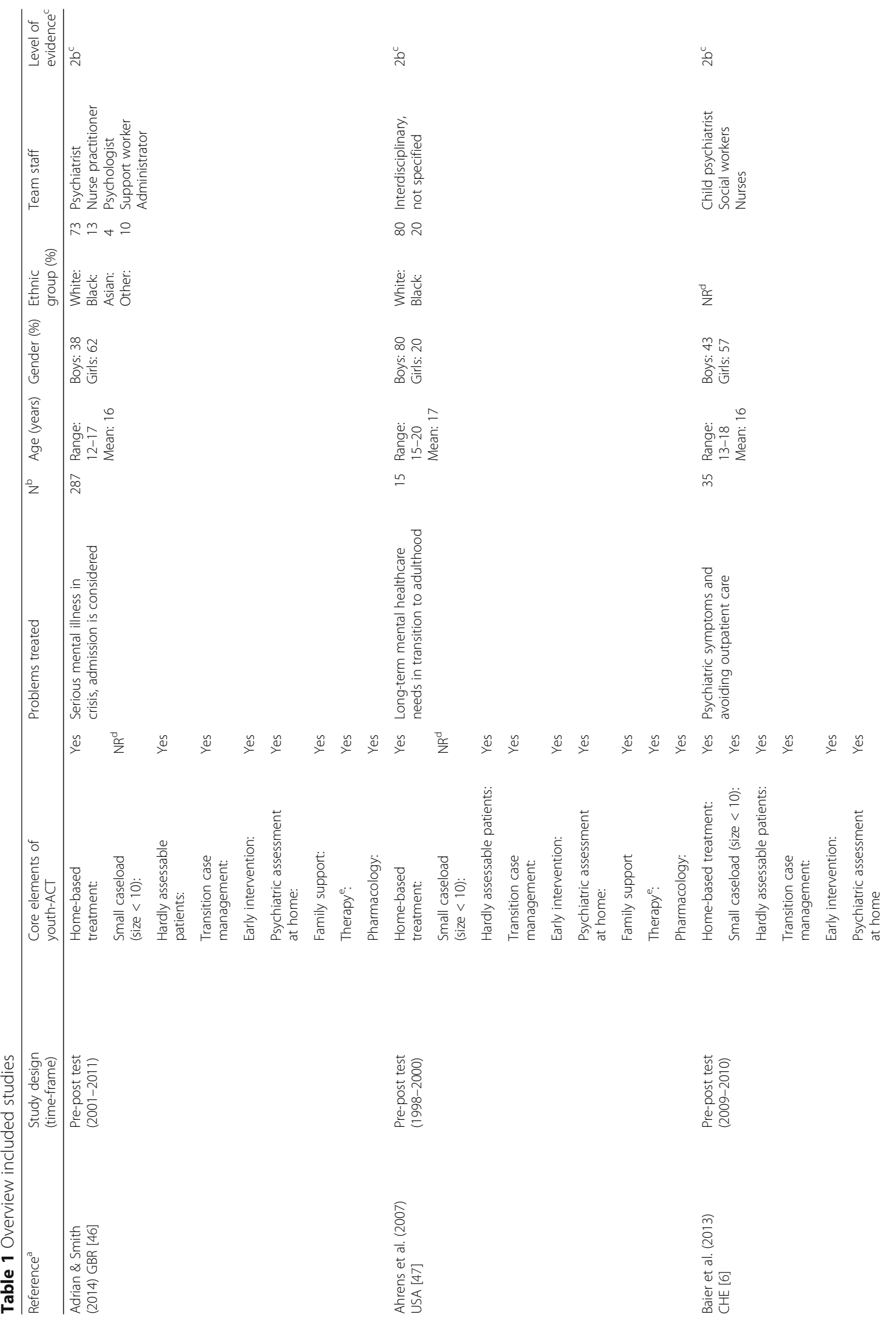




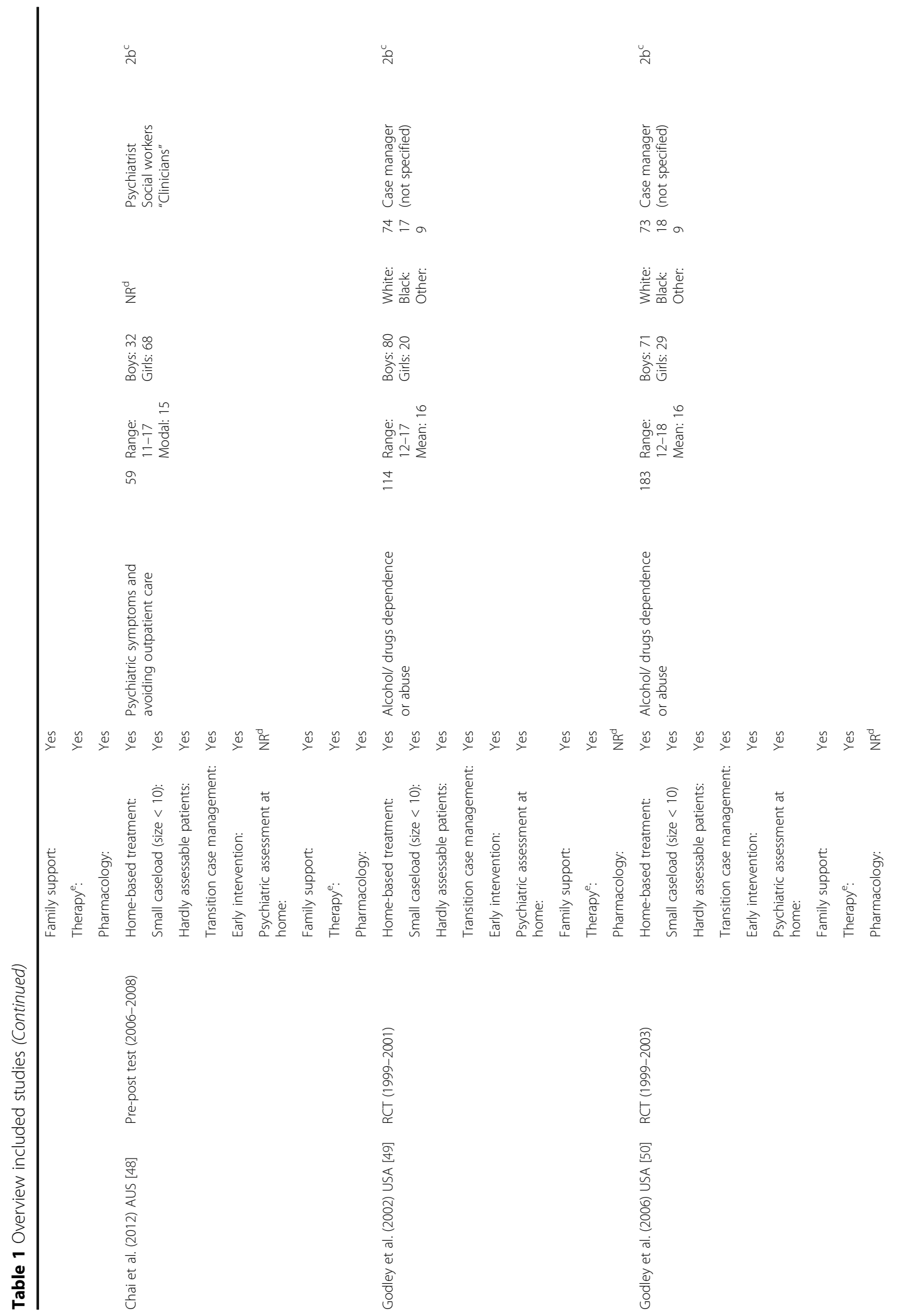




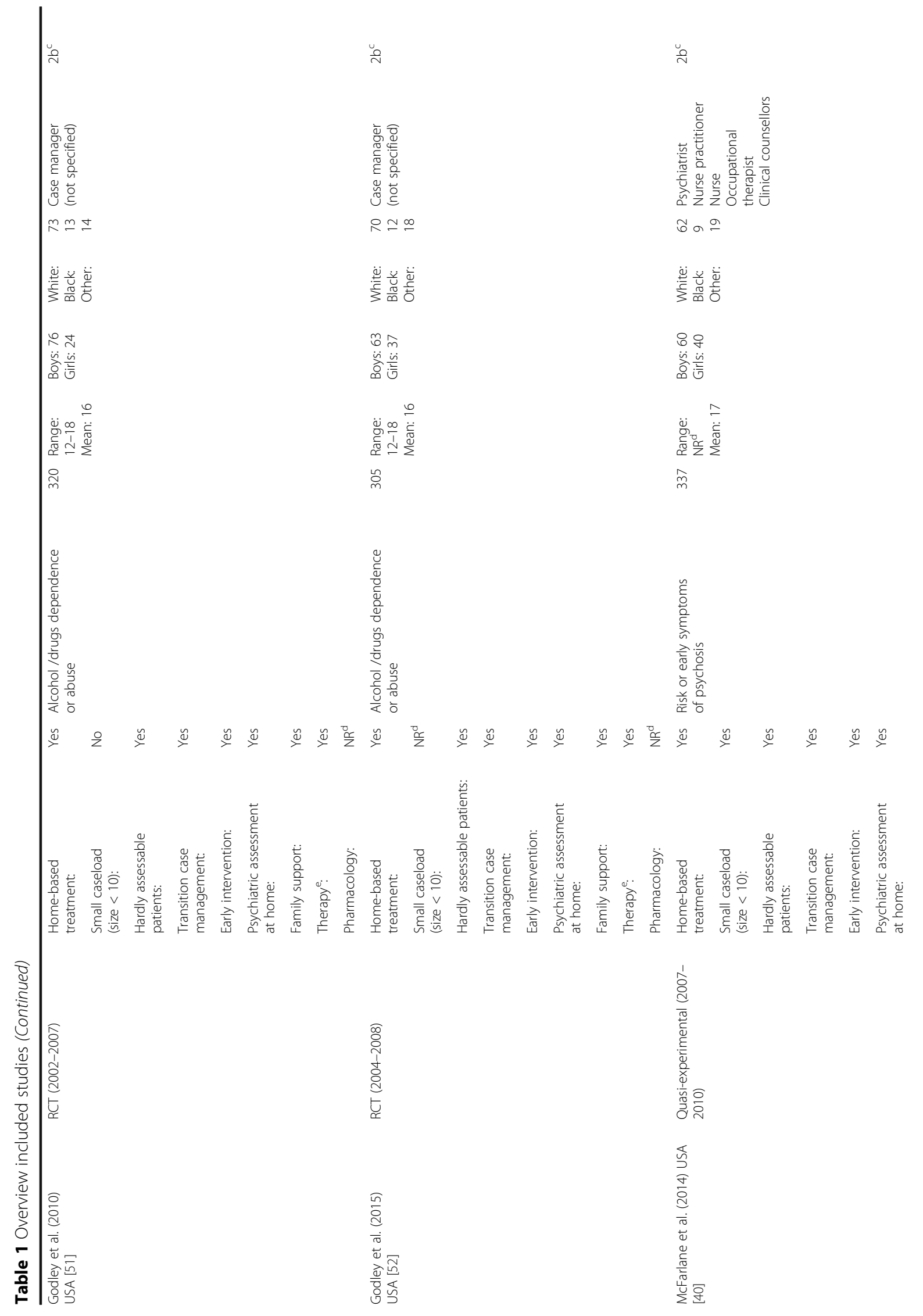


$\stackrel{u}{N}$

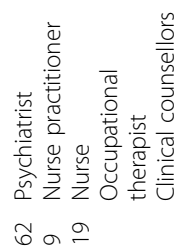

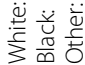

8 우

ठิ

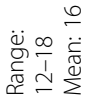

守

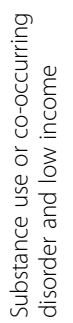

$\stackrel{\mathrm{o}}{\mathrm{N}}$

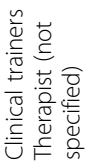

กำ

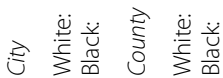

$\hat{\sim}$

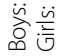

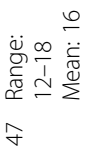

荺

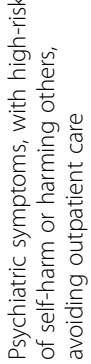

$\stackrel{\circ}{\sim}$

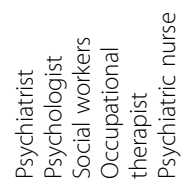

$\stackrel{0}{\stackrel{0}{z}}$

กิ

客㝘

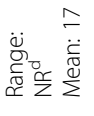

$\infty$

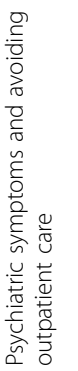

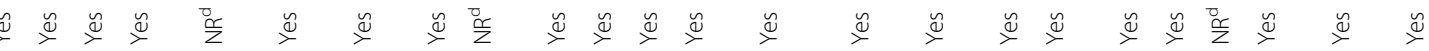

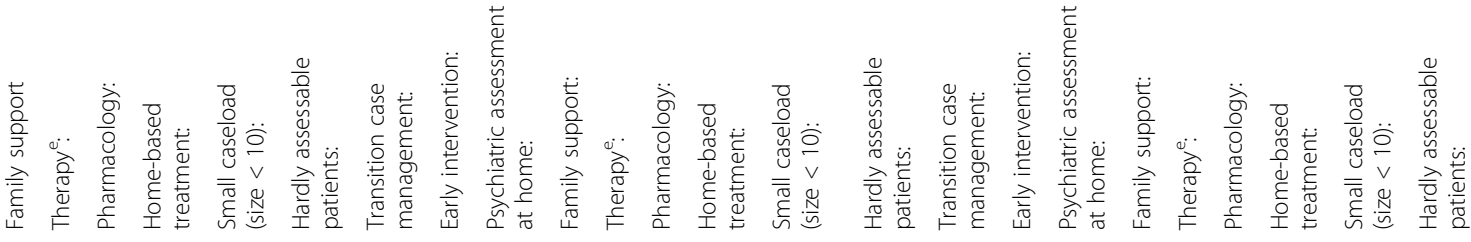

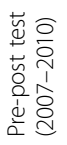

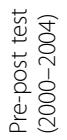

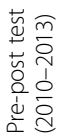

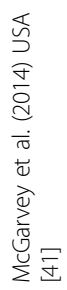

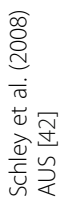

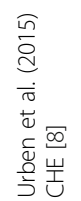


$\stackrel{u}{2}$

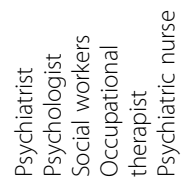

$\stackrel{0}{\stackrel{0}{Z}}$

$\bar{\sigma}$ ㄱ

苍芒芒

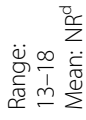

f

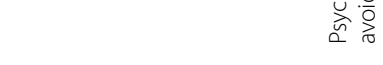

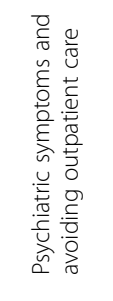

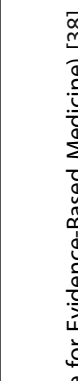

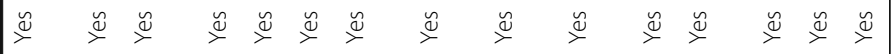

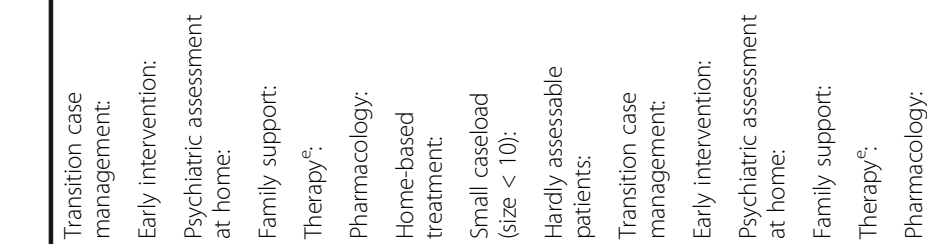

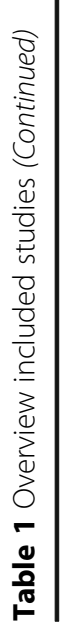

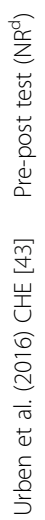

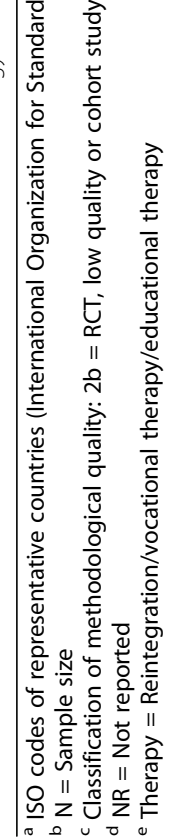


and thereby in many cases of little clinical relevance [39]. To assess clinical relevance, effect sizes (ES) of significant effects were retrieved from the papers as Cohen's d. If not reported in a paper, Cohen's d was calculated by the first author (RV) if data for this calculation were provided in the manuscript [40-43].

Effect sizes were categorized as small $(\geq 0.2-0.5)$; medium (>0.5-0.8); or large (>0.8) [44].

\section{Strength of recommendation}

The Oxford Centre of Evidence-Based Medicine grading system [38] was used to obtain an overall measure for the strength of a recommendation [45]. Overall conclusions with a high strength of recommendation are of more importance than those with a lower strength. The strength of a recommendation was considered high (grade A) if all studies with respect to a subject were classified with a level of evidence category $1 \mathrm{a}, 1 \mathrm{~b}$ or $1 \mathrm{c}$ (categories are explained in section Quality Appraisal). The strength of a recommendation was considered moderate (grade B) if studies were classified as level of evidence category $2 \mathrm{a}, 2 \mathrm{~b}, 2 \mathrm{c}, 3 \mathrm{a}$ or $3 \mathrm{~b}$. The strength of a recommendation was considered low (grade $\mathrm{C}$ ) if studies were classified in category 4 with respect to level of evidence, and very low (grade D) in case of category 5 studies [38].

\section{Results}

The initial search strategy yielded 305 papers (Fig. 1). One hundred and twenty-six papers were selected based on title and abstract. After careful review, 11 studies met the inclusion criteria. Two additional studies were identified following the checking of reference lists of these 11 studies. In total 13 studies were selected for inclusion.

All selected papers contained at least six of the nine core elements of regular ACT and are presented in Table 1. Conducting a meta-analysis was not possible because of the limited number of studies and the variety of outcome variables. Therefore, the results are presented narratively.

\section{Study designs and level of evidence}

To assess the quality of the 13 studies, study designs are specified in Table 1. Most studies had a pre-post design and lacked a control group $[6,8,41-43,46-48]$. One study used a quasi-experimental design with a control group, but patients were not randomized [40]. Four studies were RCTs that studied a mono-disciplinary variant of youth-ACT with a limited number of sessions [49-52]. Two studies used (partly) the same patients $[49,50]$. Since no systematic reviews on youth-ACT have been published to date, none of the included papers achieved high quality ratings. All studies included in this review were found to be of moderate evidence level Grade B (2b).

\section{Sample}

Sample characteristics of all included studies are presented in Table 1 . The included studies examined adolescents up to age 18, with a wide variety of psychiatric problems including substance abuse, psychotic, emotional, and developmental problems. Patients received youth-ACT as the only treatment $[6,8,40,42,43,46-48]$ or as an aftercare program $[49,50,52]$. The average ages of included patients ranged from 15 to 17 years. One study included 15 patients, some of whom were 19 or 20 years of age [47]. However, because the majority of the included patients in this study were aged 15,16 or 17 $($ mean $=16.8, \mathrm{SD} \pm 1.4)$, this paper was retained [47]. None of the reviewed studies included children below age 11. Studies were conducted in the United States [40, 41, 47, 49-52], Switzerland [6, 8, 43], Australia [42, 48], and Great Britain [46]. Most studies investigated a Caucasian sample.

Table 1 shows that girls formed a large majority in three samples $[6,46,48]$. In the other samples, boys formed the majority [8, 40-43, 47, 49-52]. In total, 774 girls and 1217 boys were included.

\section{Measurements}

The severity of psychiatric symptoms was assessed using two clinician-based instruments, the Clinical Global Impression Scale (CGI) [53] and the Health of the Nation Outcome Scales Child and Adolescents Mental Health (HoNOSCA) [54, 55]. Client-based instruments used to measure severity of psychiatric symptoms were the Global Appraisal of Individual Needs (GAIN) [56], Structured Interview for Prodromal Syndromes (SIPS) [57], Timeline Follow Back (TLFB) [58], and the Structured Clinical Interview for DSM-IV Axis I Disorders (SCID-I/CV) [59], Urine drug test or breath-analysing tests were used as biometric instruments [41, 49-52]. General functioning was measured with clinician-based instruments: the GAIN [56], Global Assessment of Functioning (GAF) [60], Children's Global Assessment Scale (CGAS) [61], and Social and Occupational Functioning Assessment Scale (SOFAS) [46] or with a subscale of HoNOSCA [54, 55]. Hospital admissions were assessed by examining medical files [46-48, 52], or by applying a client-based self-developed structured audit questionnaire [42].

\section{Effect on severity of psychiatric symptoms}

Table 2 shows that 11 studies examined the effect of youth-ACT on the severity of psychiatric symptoms $[6$, $8,40-43,46,49-52]$. Positive effects were reported in ten studies (Table 2). Youth-ACT may have the greatest 


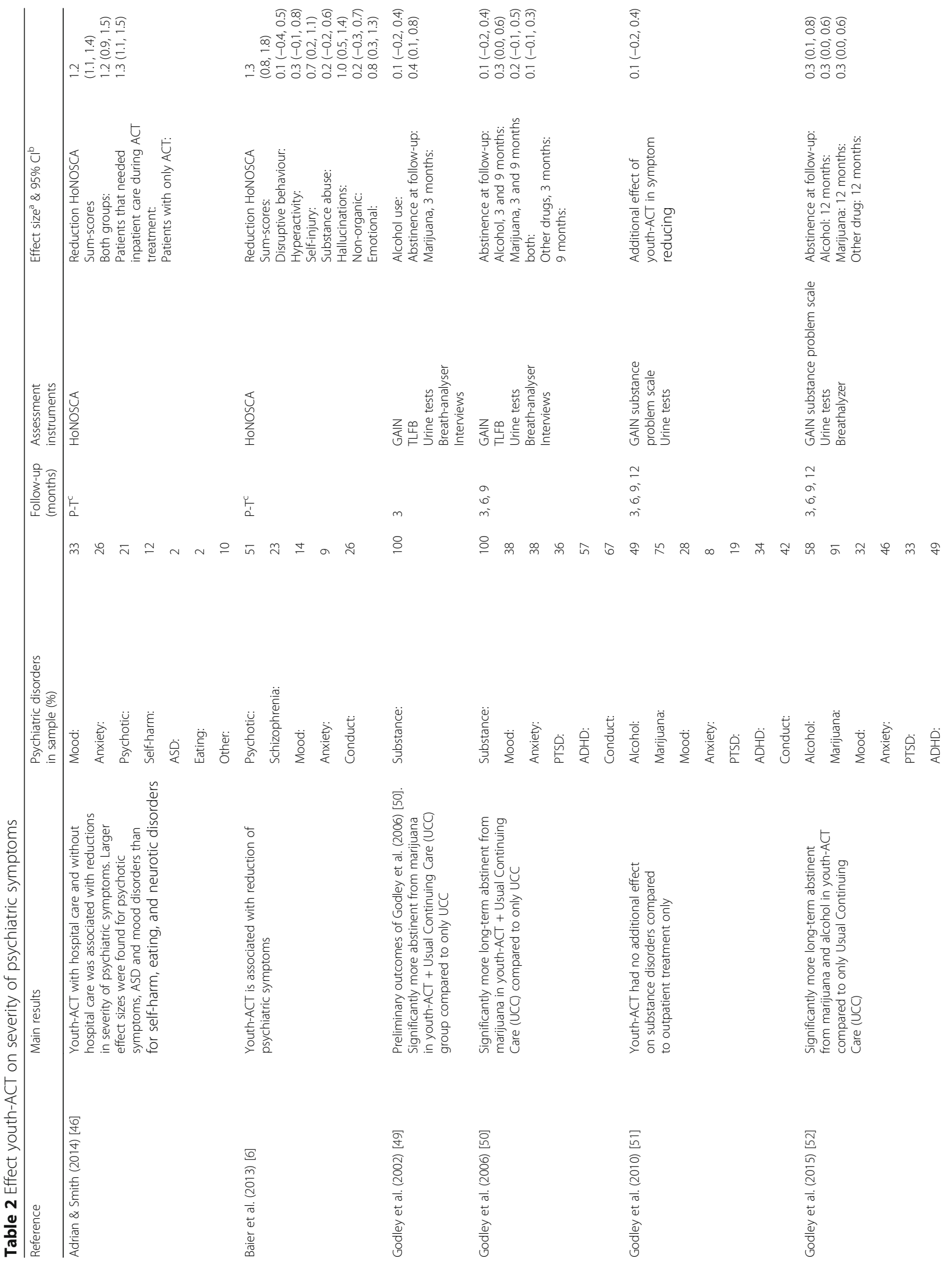




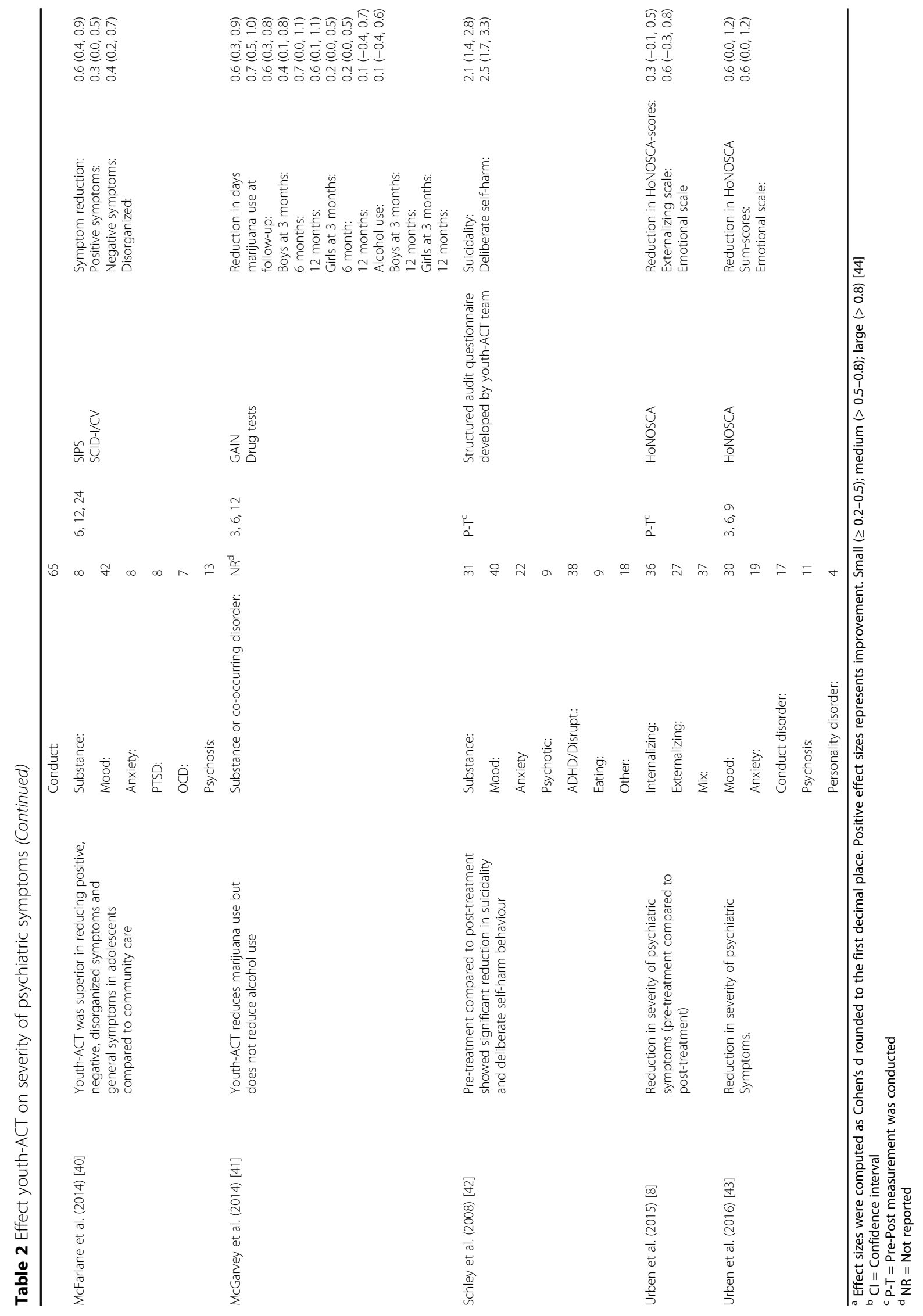


effect on psychotic symptoms, suicidality, self-harm behavior, and emotional problems. One study reported no additional effect $(\mathrm{ES}=0.1)$ when youth-ACT was added to outpatient mental healthcare [51].

\section{Psychiatric symptoms in general}

Two studies reported large effect sizes of 1.2 and 1.3 respectively $[6,46]$ and one study a medium effect size $(\mathrm{ES}=0.6$ [43]) with respect to a decrease of HoNOSCA sum-scores.

\section{Emotional problems}

Four studies (Table 2) examined the effect of youthACT on emotional symptoms [6, 8, 42, 43]. All studies found a significant reduction of emotional problems. In two studies a medium effect size of 0.6 was found, assessed with the HoNOSCA $[8,43]$. In the third study a small decrease was found in scores on the HoNOSCAitem non-organic somatic symptoms $(\mathrm{ES}=0.2)$, a medium decrease in self-injuries (ES $=0.7$ ), and a large decrease in mood symptoms $(E S=0.8)$ and emotional symptoms $(E S=0.8[6])$. The fourth study reported a large effect size in suicidality $(E S=2.1)$ and deliberate self-harm behavior $(\mathrm{ES}=2.5[42])$.

\section{Behavioral problems}

One study found a small effect $(E S=0.3)$ for the decrease in externalizing behavior assessed with the HoNOSCA [8]. Another study reported a similar small effect size for the HoNOSCA-item hyperactivity/focus problems $(E S=0.3)$, but no significant effect size on disruptive and aggressive behaviors ( $\mathrm{ES}=0.1[6])$.

\section{Psychotic problems}

Youth-ACT for patients with psychotic disorders was examined in two studies $[6,40]$. One study reported small effects with respect to negative symptoms $(E S=0.3)$ and disorganized symptoms $(E S=0.4)[40]$ assessed with the SIPS [57]. A medium effect size was reported for positive symptoms $(E S=0.6)$ using the same instrument [40]. The second study reported a large effect size $(E S=1.0)$ for the decrease in HoNOSCA item scores regarding hallucinations and delusions [6].

\section{Addiction problems}

Five studies reported on the effect of youth-ACT on addiction problems, using subscales of the GAIN [6, 41, $49,50,52]$. Three studies did not find significant reduction in alcohol abuse $(\mathrm{ES}=0.1[41,49,50])$. Two studies found a small effect size for alcohol abuse [41, 52], however in one study this was found only for boys and not for girls [41]. Four studies found a reduction in cannabis use $[41,49,50,52]$. Three of these studies, reported small effect sizes for abstinence of cannabis at the 1 month $(E S=0.3)$ and the 9 month $(E S=0.3)$ follow-up $[49,50,52]$ although two studies used (partly) the same patients [49, 50]. Also, at the 3-month follow-up, a small effect size ( $E S=0.2$ ) was found for diminishing use of drugs other than cannabis in one study [50]. No significant effect $(E S=0.1)$ was found at the 9 month follow-up [50]. One study reported a reduction in days of cannabis use at 3 month follow-up, with a medium effect size for boys $(E S=0.6)$, and a small effect size for girls $(E S=0.4[41])$. This study also reported a medium effect size for reduction in days of cannabis use for boys and girls at the 6 month follow-up ( $E S=0.7$ and 0.6 respectively), and the 12 month follow-up (ES $=0.6$ ) for both boys and girls [41].

\section{Effect on general functioning}

Table 3 shows eight studies with information about the effect of youth-ACT on general functioning [6, 40-43, $46,48,52]$. All studies reported significant improvements. Effect sizes ranged from small to large. YouthACT had the largest effect on school attendance and family relations.

Five studies investigated effects on general functioning $[6,40,43,46,52]$ : One study reported an increase in GAF-score $(E S=0.3[40])$. A second study reported a large increase in CGAS-score ( $\mathrm{ES}=1.5)$, with individuals with psychotic, mood, or autism spectrum disorders improving more than those with neurotic disorders, deliberate self-harm, or eating disorders [46]. A third study found a small effect on pro-social activities $(E S=0.2$ [52]). A fourth and fifth study reported large $(E S=1.3)$ and medium $(E S=0.6)$ effect sizes respectively, with respect to a decrease of HoNOSCA sum-scores [6, 43].

\section{School attendance}

Six studies examined school attendance [6, 40, 41, 43, $48,52]$. All studies found a significant effect of youthACT. Medium effect sizes (ES $=0.6[6]),(E S=0.7[41])$, $(\mathrm{ES}=0.7[48])$, and $(\mathrm{ES}=0.8[43])$ were reported on the HoNOSCA item school attendance, and decrease of average number of days expelled from school $(E S=0.6$ [41]). One study found a decrease of part-time school attendance, and non-attendance [40]. One study reported no significant effect on school attendance [52]. For these two studies ES could not be calculated because required data were not reported [40,52].

\section{Interpersonal relations}

Two studies examined the effect of youth-ACT on interpersonal relations $[6,52]$. One study used subscales of HoNOSCA [6]. Small effect sizes were found for peer relations $(E S=0.4)$ and family relations $(E S=0.5)$. The second study reported no significant effect on experienced family problems [52]. 
Table 3 Effect youth-ACT on general functioning

\begin{tabular}{|c|c|c|c|c|c|}
\hline Reference & Main results & $\begin{array}{l}\text { Follow-up } \\
\text { (months) }\end{array}$ & $\begin{array}{l}\text { Assessment } \\
\text { instruments }\end{array}$ & Effect size $\mathrm{a}^{\mathrm{a}}$ 95\% Cl & \\
\hline Adrian \& Smith (2014) [46] & $\begin{array}{l}\text { Compared to baseline } 50 \% \text { of the } \\
\text { adolescents treated with youth-ACT } \\
\text { showed improvement in general } \\
\text { functioning according to CGAS score } \\
\text { at discharge. Adolescents with psychotic } \\
\text { and mood disorders improved } \\
\text { more that patients with neurotic } \\
\text { disorders }\end{array}$ & $P-T^{c}$ & CGAS & $\begin{array}{l}\text { Baseline compared with } \\
\text { discharge CGAS-scores: } \\
\text { ACT combined with } \\
\text { inpatient care: } \\
\text { Only ACT: }\end{array}$ & $\begin{array}{l}1.3(1.0,1.6) \\
1.5(1.3,1.7)\end{array}$ \\
\hline Baier et al. (2013) [6] & $\begin{array}{l}\text { Youth-ACT associated with significant } \\
\text { improvement in social functioning } \\
\text { measured with HoNOSCA (school } \\
\text { attendance, and peer and family } \\
\text { relations) }\end{array}$ & $P-T^{c}$ & HoNOSCA & $\begin{array}{l}\text { HoNOSCA-scores: } \\
\text { Sum-score: } \\
\text { Peer relations: } \\
\text { Family relations: } \\
\text { School attendance: }\end{array}$ & $\begin{array}{l}1.3(0.8,1,8) \\
0.4(0.0,0.9) \\
0.5(0.0,1.0) \\
0.6(0.1,1.1)\end{array}$ \\
\hline Chai et al. (2012) [48] & $\begin{array}{l}\text { Significant improvement in clinician-rated } \\
\text { levels of social functioning. Adolescents } \\
\text { treated with youth-ACT showed } \\
\text { increase in school attendance }\end{array}$ & $P-T^{c}$ & $\begin{array}{l}\text { CGAS } \\
\text { School attendance registration form }\end{array}$ & School attendance: & $0.7(0.4,1.1)$ \\
\hline Godley et al. (2015) [52] & $\begin{array}{l}\text { Small significant improvement in } \\
\text { pro-social activities. No significant } \\
\text { differences in school attendance } \\
\text { and family problems }\end{array}$ & $3,6,9,12$ & GAIN & Pro-social activities: & $0.2(-0.2,0.4)$ \\
\hline McFarlane et al. (2014) [40] & $\begin{array}{l}\text { Adolescents with psychotic symptoms } \\
\text { treated with youth-ACT showed } \\
\text { significantly higher GAF-outcomes, } \\
\text { increased school attendance or work } \\
\text { (21\%) compared to those who received } \\
\text { Community Care (7.0\%) }\end{array}$ & $6,12,24$ & GAF & GAF-score: & $0.3(0.0,0.5)$ \\
\hline McGarvey et al. (2014) [41] & $\begin{array}{l}\text { Decrease in average number of days } \\
\text { missing school } \\
\text { ( } 5.3 \text { to } 2.6 \text { days) or being expelled } \\
\text { from school ( } 0.2 \text { to } 0.01 \text { days) } \\
\text { compared to baseline }\end{array}$ & $3,6,12$ & GAIN & $\begin{array}{l}\text { School attendance: } \\
\text { Decrease in days } \\
\text { expelled from school: }\end{array}$ & $\begin{array}{l}0.7(0.4,1.1) \\
0.6(0.3,0.9)\end{array}$ \\
\hline $\begin{array}{l}\text { Schley et al. } \\
\text { (2008) [42] }\end{array}$ & $\begin{array}{l}\text { Youth-ACT decreased the frequency of } \\
\text { violence and crime }\end{array}$ & $P-T^{c}$ & $\begin{array}{l}\text { Structured } \\
\text { self-developed questionnaire }\end{array}$ & $\begin{array}{l}\text { Crime: } \\
\text { Violence: }\end{array}$ & $\begin{array}{l}0.6(0.1,1.2) \\
0.9(0.3,1.5)\end{array}$ \\
\hline $\begin{array}{l}\text { Urben et al. } \\
\text { (2016) [43] }\end{array}$ & $\begin{array}{l}\text { Adolescents treated with youth-ACT } \\
\text { showed significant improvements } \\
\text { in HoNOSCA social-score which } \\
\text { include the items family relations, } \\
\text { peer relations and school attendance. }\end{array}$ & $3,6,9$ & HoNOSCA & $\begin{array}{l}\text { HoNOSCA } \\
\text { Sum score: } \\
\text { Social-score: } \\
\text { School attendance: }\end{array}$ & $\begin{array}{l}0.6(0.0,1.2) \\
0.8(0.1,1.2) \\
0.8(0.2,1.4)\end{array}$ \\
\hline
\end{tabular}

${ }^{a}$ Effect sizes were computed as Cohen's d rounded to the first decimal place. Positive effect sizes represents improvement. Small ( $\left.\geq 0.2-0.5\right)$; medium (>0.5-0.8); large (>0.8) [44]

${ }^{\mathrm{b}} \mathrm{Cl}=$ Confidence interval

${ }^{\mathrm{C}} \mathrm{P}-\mathrm{T}=$ Pre-Post measurement was conducted

\section{Effect on psychiatric hospital admissions}

All five studies reporting the effect of youth-ACT on frequency and duration of psychiatric hospital admissions found a significant effect (Table 4) [42, 46-48, 52].

\section{Frequency}

Three studies examined the effect on frequency of admissions $[42,46,48]$. One study examined the frequency and duration of psychiatric hospital admissions during three-monthly intervals over a period of 12 months prior and post youth-ACT treatment [42]. This study showed that, with youth-ACT, the frequency of admissions decreased $7 \%$ at 3 month, $29.4 \%$ at 6 month, and $27.6 \%$ at 9 month follow-up. No significant effects were found at 12 months [42]. Another study found a decrease of admission rates $(E S=1.0)$ in patients who received youth-ACT [48]. A third study reported that youth-ACT resulted in a decrease in hospital admissions [46]. For this study ES could not be calculated because required data were not reported.

\section{Duration}

Table 4 shows that four studies examined the effect of youth-ACT on duration of hospital admissions [42, 46, $47,52]$. Reduction in duration of hospital admission was reported in all four studies. In one study small effect sizes were found for a decrease of days in hospitals at 12 month follow-up [52]. A second study found medium effect sizes for a decrease in duration of hospital admissions $(E S=0.5)$ and days spent in psychiatric institutions $(E S=0.6$ [47]). Another study found large effect sizes at 3 month (ES = 1.6), 6 month (ES = 1.1) follow-up, and a medium effect size at 12 month $(E S=0.7)$ follow-up [42]. A fourth study reported that youth-ACT resulted 
Table 4 Effect youth-ACT on psychiatric hospital admissions

\begin{tabular}{|c|c|c|c|c|c|}
\hline Reference & Main results & Follow-up (months) & Assessment instruments & Effect size $^{a} \& 95 \%{C l^{b}}^{b}$ & \\
\hline $\begin{array}{l}\text { Adrian \& Smith } \\
\text { (2014) [46] }\end{array}$ & $\begin{array}{l}\text { Youth-ACT associated with reduction } \\
\text { in length of hospital admission }\end{array}$ & 12 & Medical files & $N R^{c}$ & \\
\hline $\begin{array}{l}\text { Ahrens et al. } \\
\text { (2007) [47] }\end{array}$ & $\begin{array}{l}\text { Reduction in number of hospitalized } \\
\text { days. Decrease in total number of } \\
\text { days of inpatient psychiatric } \\
\text { treatment, forensic treatment } \\
\text { or incarceration }\end{array}$ & 24 & Medical files & $\begin{array}{l}\text { Reduction admission days: } \\
\text { Reduction in time in } \\
\text { institutions, inpatient psychiatric } \\
\text { treatment, and forensic treatment } \\
\text { or incarceration: }\end{array}$ & $\begin{array}{l}0.5(-0.2,1.3) \\
0.6(-0.3,1.4)\end{array}$ \\
\hline $\begin{array}{l}\text { Chai et al. } \\
\text { (2012) [48] }\end{array}$ & $\begin{array}{l}\text { Significant reduction in rates of } \\
\text { admission in the youth-ACT sample. } \\
\text { Percentage of adolescents with no } \\
\text { admissions increased from } 53 \% \\
\text { prior to referral to } 83 \% \text { post treatment }\end{array}$ & $P-T^{d}$ & Medical files & Reduction admissions: & $1.0(0.5,1.6)$ \\
\hline $\begin{array}{l}\text { Godley et al. } \\
\text { (2015) [52] }\end{array}$ & $\begin{array}{l}\text { Significant fewer days spent in } \\
\text { residential treatment, juvenile } \\
\text { detention, and hospitals over the } \\
12 \text { month follow-up period compared } \\
\text { to UCC }\end{array}$ & $3,6,9,12$ & Medical files & Reduction admission days: & $0.3(0.1,0.6)$ \\
\hline $\begin{array}{l}\text { Schley et al. } \\
\text { (2008) [42] }\end{array}$ & $\begin{array}{l}\text { Comparison of psychiatric hospital } \\
\text { admission rates and average number } \\
\text { of days in the hospital prior to and } \\
\text { after youth-ACT treatment showed } \\
\text { that admission rates decreased with } \\
17 \% \text { at } 3 \text { month, } 29 \% \text { at } 6 \text { month, } \\
28 \% \text { at } 9 \text { month and } 22 \% \text { at } \\
12 \text { month follow-up }\end{array}$ & $3,6,9,12$ & $\begin{array}{l}\text { Structured self-developed } \\
\text { questionnaire }\end{array}$ & $\begin{array}{l}\text { Reduction in hospital } \\
\text { admissions days: } \\
3 \text { months: } \\
6 \text { months: } \\
12 \text { months: }\end{array}$ & $\begin{array}{l}1.6(1.2,2.1) \\
1.1(0.7,1.5) \\
0.7(0.1,1.2)\end{array}$ \\
\hline
\end{tabular}

$\left.{ }^{\mathrm{a} E f f e c t ~ s i z e s ~ w e r e ~ c o m p u t e d ~ a s ~ C o h e n ' s ~ d ~ r o u n d e d ~ t o ~ t h e ~ f i r s t ~ d e c i m a l ~ p l a c e . ~ P o s i t i v e ~ e f f e c t ~ s i z e s ~ r e p r e s e n t s ~ i m p r o v e m e n t . ~ S m a l l ~(~} \geq 0.2-0.5\right)$; medium ( $>$ $0.5-0.8)$; large (>0.8) [44]

${ }^{\mathrm{b}} \mathrm{Cl}=$ Confidence interval

${ }^{\mathrm{C}} \mathrm{NR}=$ Not reported

${ }^{\mathrm{d}} \mathrm{P}-\mathrm{T}=$ Pre-Post measurement was conducted

in significantly shorter hospital admissions [46]. For this study ES could not be calculated because required data were not reported.

\section{Discussion}

This review summarises the outcomes of 13 studies examining the effects of youth-ACT on severity of psychiatric symptoms, general functioning, and frequency and duration of psychiatric hospital admissions.

\section{Clinical implications}

There are indications that youth-ACT is effective with respect to diminishing the severity of psychiatric symptoms in adolescents. Effect sizes range from small to large.

The single study that did not yield a significant effect was a RCT that found that youth-ACT had no additional effect if applied as a supplement to office-based mental healthcare [51]. This study consisted of an intervention that was limited to an average of only five to eight sessions. This low number of sessions may explain the lack of effect [39]. Because ACT in adults seems more effective in patients with severe problems [23], another explanation could be that the included patients in this study had relatively mild problems [39]. Also, it could be that ACT was compared to another intervention, in this particular case a behavioral therapeutic intervention, which was very effective with respect to substance abuse. In other words, there was no clear contrast between experimental and control group regarding therapeutic efforts.

\section{Emotional problems}

Some studies showed that youth-ACT is beneficial for adolescents with emotional problems [6, 8, 42, 43]. Studies concerning ACT in adults found effects on emotional problems that range from small $(E S=0.2[20])$ to medium $(E S=0.5[28])$. In youths, effects vary from small to large which could mean that ACT may be more effective in addressing emotional problems in children and adolescents.

Guidelines for emotional problems (anxiety or depression) in children and adolescents, for example the NICE guideline "Depression in children and young people" [62], do not provide recommendations with respect to youth-ACT. Children with emotional problems can be difficult to reach by outpatient care, because of avoidance (in case of anxiety) or depression (due to lack of energy, or loss of interest, for instance, in school, work or friends). Children with severe emotional problems have an increased risk of psychiatric hospitalization [63]. Youth-ACT teams can actively approach these children in their own living environment, instead of leaving them at home, without offering treatment, which may result 
in an increase in depression and anxiety, and ultimately, self-harm behaviors, increased parental stress, and hospitalization [64]. Youth-ACT might be a suitable approach for early screening, diagnosis, and treatment of care for children and adolescents with anxiety disorders or depression [64].

\section{Behavioral problems}

There is no evidence that youth-ACT is effective for disruptive and aggressive behaviors [6]. This conclusion is based on one study. If outreach treatment is needed, Multi Systemic Therapy (MST) $[65,66]$ or Multidimensional Family Treatment (MDFT) [67] may be more appropriate in accordance with the NICE guideline "Antisocial behavior and conduct disorders in children and young people" [68].

\section{Psychotic problems}

Two studies indicate that youth-ACT is effective in reducing psychotic symptoms $[6,40]$. Effect sizes range from small to large. In adults, effects range from not significant $(E S=0.1[20])$ to medium $(E S=0.5[22])$. This may mean that in youth, ACT may be more effective. Children and adolescents with psychotic disorders have an increased risk of psychiatric hospitalization [69] and their long-term prognosis is often poorer than in adults [70]. Youth-ACT might play a key role in limiting longterm disability by providing early diagnostics and intervention [71]. The use of assertive case management for psychotic problems in adolescents is in accordance with existing guidelines, such as the NICE guideline "Psychosis and schizophrenia in children and young people" [14] and Orygen guideline "Australian clinical guidelines for early psychosis" [72].

\section{Addiction problems}

Youth-ACT appears effective in reducing cannabis use, and can be applied in case of care avoidance of children and adolescents [41, 49, 50,52]. This conclusion is in accordance with the NICE guideline "Drug misuse in over 16s: psychosocial interventions" [73].

Unlike for adults, where effect sizes ranged from medium $(\mathrm{ES}=0.5[25])$ to large $(\mathrm{ES}=0.9[25] ; \mathrm{ES}=1.5$ [24]), a majority of the studies in youths found no evidence that youth-ACT is effective for alcohol abuse. However, it has to be noted that only a limited number of studies examined these effects. Nevertheless, and similar as in adults [74], youth-ACT is used to support care-avoiding adolescents with severe alcohol abuse who do not benefit from other intensive treatment programs $[3,75]$. The NICE guideline "Alcohol-use disorders: diagnosis, assessment and management of harmful drinking and alcohol dependence" recommends Assertive Outreach for adolescents [76]. Based on current evidence, the question arises whether it is appropriate to apply youthACT in adolescents with treatment resistant alcohol abuse. More research is needed.

Youth-ACT appears to improve general functioning in adolescents with severe psychiatric symptoms [6, 41-43, $46,48,52]$. Effects seem comparable with studies investigating $\mathrm{ACT}$ in adults that found small $(\mathrm{ES}=0.2[25]$; $\mathrm{ES}=0.3[21])$, medium $(\mathrm{ES}=0.6[22])$ and large $(\mathrm{ES}=1.7$ [24]) effects. Large significant effects on general functioning coincided with large effects on psychotic symptoms and mood disorders.

\section{School attendance}

There are indications that youth-ACT improves school attendance $[6,40,41,43,46,48]$. It may be seen as encouraging that three studies with respect to school attendance found positive effects, since absenteeism is associated with an increase in severity of psychiatric symptoms, dropout from school, and unemployment $[59,77,78]$.

\section{Interpersonal relations}

Youth-ACT may improve interpersonal relations [6]. Effects on family relations are small, however slightly larger, these effects are comparable with adults $(E S=0.3$ [19]). Youth-ACT programs focus on participation in the community, since adolescents with severe psychiatric symptoms often have a small social network and weak social support, which can be attributed to a high levels of impairment in social functioning [36, 79].

\section{Hospital admissions}

Youth-ACT appears to reduce duration and frequency of psychiatric hospital admissions [42, 46-48, 52]. This is of interest, because children and adolescents with severe psychiatric symptoms are at a higher risk of being hospitalized than adults with similar problems [11]. Similar to adults where effects range from small $(E S=0.2[23])$, medium $(E S=0.4[25])$ to large $(E S=1.9[27,80])$, youth-ACT may contribute to deinstitutionalization $[1,2]$ and higher cost-effectiveness. In addition, fewer hospital admissions may be associated with better social functioning, since adolescents are not "removed" from their social environment [71]. This is in line with the finding that youth-ACT may help to improve interpersonal relations [6].

\section{Strengths and limitations}

This review has several strengths. First, it is the first review to date describing effectiveness of youth-ACT. Evidence has been summarized regarding current knowledge about its effects on psychiatric symptoms, general functioning, and hospital admissions. Second, studies were 
selected and assessed on their core elements of youth$\mathrm{ACT}$, to avoid missing relevant information.

Limitations pertain to the number and quality of studies published so far. However, despite this limitation, clear patterns are visible and unambiguous trends have been found in favor of youth-ACT.

According to the Oxford Centre of Evidence-Based Medicine grading system [38] all overall conclusions received a moderate strength of recommendation (grade B). Another drawback is that a majority of the studies were conducted in the United States which might hamper generalizability of findings to countries outside the United States [39, 81].

\section{Recommendations}

Randomized controlled trials (RCTs) in different countries are needed to obtain grade A knowledge about the effect of youth-ACT. Such studies should also include children below the age of 12 years. The focus should be on a wide range of outcomes, including psychopathology and social functioning in several areas. Future studies should report on model fidelity to obtain a better insight into specific content of the youth-ACT program. The Dartmouth Assertive Treatment Scale (DACT) [5, 7] can be used for this purpose. Finally, although youth-ACT programs use a family approach, none of the studies provide detailed information about psychiatric and psychosocial problems of family members. Insight into these problems is needed, since such problems are likely to be present given familial aggregation of psychiatric disorders [82], and may influence treatment outcome.

\section{Conclusion}

The findings of the studies included in this literature review are promising, despite the limitations described with respect to study designs. There are indications that youth-ACT is effective in reducing severity of psychiatric symptoms, improving general functioning, and reducing duration and frequency of psychiatric hospital admissions. Implementation of youth-ACT is high on the political and mental health agenda, which stresses the need for more research on its effectiveness using rigorous research designs.

\section{Additional file}

Additional file 1: "Search strings review youth-ACT". (DOCX $15 \mathrm{~kb}$ )

\section{Abbreviations}

ACT: Assertive community treatment; AUS: Australia; CGAS: Children's global assessment scale; CGI: Clinical global impression scale; CHE: Switzerland; DACTS: Dartmouth assertive treatment scale; DSM: Diagnostic systematic manual of mental disorders; EAHC: Executive agency for health and consumers; ES: Effect size; GAF: Global assessment of functioning; GAIN: Global appraisal of individual needs; GBR: Great Britain;
HoNOSCA: Health of the nation outcome scales child and adolescents mental health; ISO: International Organization for Standardization; MDFT: Multidimensional family treatment; MST: Multi systemic therapy; NICE: The National Institute for health and care excellence; RCT: Randomized controlled trial; SCID-I: Structured clinical interview for DSM-IV axis I disorders; SD: Standard deviation; SIPS: Structured interview for prodromal syndromes; SOFAS: Social and occupational functioning assessment scale; TLFB: Timeline follow back; UCC: Usual continuing care; USA: United States of America; WHO: World Health Organization

\section{Acknowledgements}

We would like to thank librarian Jurgen Mollema for his assistance with building the searching-strings. We thank Marlene Stewart, Anne-tje Ouwehand, Monica Simon, and Adriaan Hoogendoorn for their valuable comments on this paper.

Funding

This research was funded by GGZ-Delfland.

Availability of data and materials

Not applicable.

\section{Authors' contributions}

$R V, R F, A B$ and $B M$ designed this study. RV and BM contributed substantially to the design of the search strategy. RV and RF searched and selected the relevant publications. Data extraction was conducted by RV and checked by RF. RV and RF performed the analysis and interpreted the data. RV and RF wrote the manuscript. BM and $A B$ critically revised it. All authors read and approved the final manuscript.

Ethics approval and consent to participate

Not applicable.

Consent for publication

Not applicable.

Competing interests

The authors declare that they have no competing interests.

\section{Publisher's Note}

Springer Nature remains neutral with regard to jurisdictional claims in published maps and institutional affiliations.

\section{Author details}

'Department of Child and Adolescent Psychiatry, GGZ-Delfland, PO-box 5016, 2600, GA, Delft, The Netherlands. ${ }^{2}$ VU Medical Centre/GGZ-InGeest, Amsterdam, The Netherlands. ${ }^{3}$ Department of Psychiatry, Amsterdam Public Health Research Institute, VU University Medical Center, Amsterdam, The Netherlands. ${ }^{4}$ Inholland University of Applied Sciences, Amsterdam, The Netherlands. ${ }^{5}$ Parnassia Psychiatric Institute, The Hague, The Netherlands.

Received: 13 March 2017 Accepted: 26 July 2017

Published online: 02 August 2017

References

1. Becker K, Kilian R. Psychiatric services for people with severe mental illness across western Europe. What can be generalized from current knowledge about differences in provision, cost and outcomes of mental health care? Acta Psychiat Scand. 2006;113:9-16. doi:10.1111/j.1600-0447.2005.00711.x.

2. Lamb H, Bachrach L. Some perspectives on deinstitutionalization. Psychiatr Serv. 2001:52:1039-45. http://dx.doi.org/10.1176/appi.ps.52.8.1039

3. WONCA Health Organization of Family Doctors. Integrated mental health into primary care: a global perspective; 2008.

4. Stein L, Test M. Alternative to mental hospital tratment: conceptual model, treatment program, and clinical evaluation. Arch Gen Psychiatry. 1980;37:392-7.

5. van Vugt M. Assertive community treatment in the Netherlands. Rotterdam: Erasmus University Rotterdam; 2015.

6. Baier V, Favrod J, Ferrari P, Koch N, Holzer L. Early tailored assertive community case management for hard-to-engage adolescents suffering from psychiatric disorders: an exploratory pilot study. Early Interv Psychiatry. 2013;7:94-9. doi:10.1111/j.1751-7893.2012.00380.x. 
7. Teague $G$, Bond $G$, Drake R. Program fidelity in assertive community treatment: development and use of a measure. Am J Orthop. 1998;68:216-31. doi:org/10.1037/h0080331

8. Urben S, Baier V, Mantzouranis G, Pigois E, Graap C, Dutoit F, et al. Predictors and moderators of clinical outcomes in adolescents with severe mental disorders after an assertive community treatment. Child Psychiatry Hum Dev. 2015;46:997-1005. doi:10.1007/s10578-015-0537-z.

9. Dieterich $M$, Irving D, Park C, Marshall M. Intensive case management for severe mental illness. Cochrane Db Syst Rev. 2010;10:CD007906. doi:10.1002/ 14651858.CD007906.pub2.

10. World Health Organization. WHO, Europe: Policies and practices for mental health in Europe. Meet the challenges, 2008. http://www.euro.who.int/_ data/assets/pdf_file/0006/96450/E91732.pdf. Accessed 14 Oct 2016.

11. Braddick F, Carral V, Jenkins R, Jané-Llopis E. Child and adolescent mental health in Europe: infrastructures, policy and programs. Luxembourg: European Communities; 2009.

12. Sillivan G, Layte R, Burfeind C, McDaid D, Salize H, Daumerie N, et al. Promoting social inclusion and combating stigma for better health and well-being backround document to the European Commission Thematic Conference 2010. European Commission, 2010. http://ec.europa.eu/health/ mental_health/policy/index_en.htm. Accessed 14 Nov 2016.

13. World Health Organization. Child and adolescent mental health policies and plans, 2005.

14. National Institute for Health and Care Excellence. Psychosis and schizophrenia in children and young people: Recognition and management, 2013. http:// www.nice.org.uk/guidance. Accessed 16 Sept 2016.

15. National Centre for Health Outcomes Development. Outcome indicators for severe mental illness. 2000. http://nchod.uhce.ox.ac.uk/mentalillness.pdf. Accessed 1 May 2017.

16. National Institute for Health and Care Excellence. Bipolair disorder: the assessment and management of bipolar disorders in adults, children and young people in primary and secondary care, 2013. http//https://www.nice. org.uk/guidance. Accessed 15 Sept 2016.

17. Horatio European Psychiatric Nurses. Horatio Position Paper, 2010. http://ec. europa.eu/health/mental_health/docs/horatio_paper_youth_en.pdf. Accessed 11 Oct 2016

18. Executive Agency for Health and Consumers; DG SANCO. Child and adolescent mental health in enlarged European Union. European Union, 2011. http://www.ec.europa.eu/health. Accessed 20 Sept 2016.

19. McCrone $\mathrm{P}$, Killaspy $H$, Bebbington $\mathrm{P}$, Johnson S, Nolan F, Pilling S, et al. The REACT study: cost-effectiveness analysis of assertive community treatment in North London. Psychiatr Serv. 2009;60(7):908-13. doi:10.1176/appi.ps.60.7.908.

20. Jerrell JM, Ridgely MS. Evaluating changes in symptoms and functioning of dually diagnosed clients in specialized treatment. Psychiatr Serv. 1995;46(3): 233-8. doi:10.1176/ps.46.3.233.

21. Lafave HG, de Souza HR, Gerber GJ. Assertive community treatment of severe mental illness: a Canadian experience. Psychiatr Serv. 1996:47(7):7579. doi:10.1176/ps.47.7.757

22. Tempier R, Balbuena L, Garety P, Craig TJ. Does assertive community outreach improve social support? Results from the Lambeth study of early-episode psychosis. Psychiatr Serv. 2012;63(3):216-22. doi:10.1176/appi.ps.20110013.

23. Ziguras SJ, Stuart GW. A meta-analysis of the effectiveness of mental health case-management over 20 years. Psychiatr Serv. 2000;51(11):1410-2. doi:10. 1176/appi.ps.51.11.1410.

24. Essock SM, Mueser KT, Drake RE, Covell NH, McHugo GJ, Frisman LK, et al. Comparison of ACT and standard casemanagement for delivering integrated treatment for co-occuring disorders. Psychiatr Serv. 2006;57(2): 185-96. doi:10.1176/appi.ps.57.185.

25. McHugo GJ, Drake RE, Teague GB, Xie H. Fidelity to assertive community treatment and client outcomes in the New Hampshire dual disorders study. Psychiatr Serv. 1999;50(6):818-24. doi:10.11176/ps.50.6.818.

26. Marks IM, Connolly J, Muijen M, Audini B, McNamee G, Lawrence RE. Homebased versus hospital-based care for people with serious mental illness. Brit J Psychiatry. 1994;165(2):179-94. doi:10.1192/bjp.165.2.179.

27. Bond GR, Miller LD, Krumwied RD, Ward RS. Assertive case Management in Three CMHCs: a controlled study. Psychiatr Serv. 1988;39(4):411-8. doi:10.1176/ps.39.4.411.

28. Morse GA, Calsyn RJ, Klinkenberg WD, Trusty ML, Gerber F, Smith R, et al. An experimental comparison of three types of case management for homeless mentally ill persons. Psychiatr Serv. 1997:48(4):497-503. doi:10.1176/ps.48.4.497.
29. Nelson G, Laurier W, Aubry T, Lafrance A. Review of the literature on the effectiveness of housing and support, assertive community treatment, and intensive case management interventions for persons with mental illness who have been homeless. Am J Psychiatry. 2007;77(3):350-61. doi:10.1037/0002-9432.77.3.350.

30. Burns T, Catty J, Dash M, Robberts C, Lockwood A, Marshall M. Use of intensive case management to reduce time in hospital in people with severe mental illness: systematic review and meta-regression. BMJ. 2007; 335(7615):336-40. doi:10.1136/bmj.39251.599259.55.

31. Rosen A, Mueser KT, Teesson M. Assertive community treatment-issues from scientific and clinical literature with implications for practice. Rehabil Res Dev. 2007;44:813-26.

32. Moher D, Liberati A, Tetzlaff J, Altman DG. The PRISMA group. Preferred Reporting Items for Systematic reviews and Meta-Analyses: The PRISMA Statement. PLoS Med. 2009;6:e1000097. doi:10.1371/journal.pmed.1000097.

33. Steijn D, Philips A, Folford K, Sadler J, Kendler S. What is a mental/psychiatric disorder? From DSM-IV to DSM-V. J Psychol Med Ment Pathol. 2010;11(40): 759-65. doi:10.1017/S0033291709992261.

34. Yager J, Ehmann T. Untangling social functioning and social cognition: a review of concepts and measurement. Psychiatry. 2006;69:47-68. doi:10.1521/psyc.2006.69.1.47.

35. Verhulst FC. Ontwikkeling van het kind (development of a child). Assen: Koninklijke van Gorcum; 2005.

36. Hoza B, Mrug S, Gerdes A, Hinshaw S, Bukowski B, Gold J, et al. What aspect of peer relationships are impaired in children with attention-deficit/ hyperactivity disorder? J Consult Clin Psychol. 2005;73(3):411-23. doi:10.1037/0022-006X.73.3.411.

37. Czuchry M, Dansereau DF, Sia TL, Simpson DD. Using peer, self, and counselor ratings to evaluate treatment progress. J Psychoactive Drugs. 1998;30(1):81-7. doi:10.1080/02791072.1998.10399673.

38. Oxford Centre for Evidence-based Medicine. Oxford Centre for Evidencebased Medicine-Levels of Evidence. 2009. http://www.cebm.net/oxfordcentre-evidence-based-medicine-levels-evidence-march-2009/. Accessed 14 Oct 2016

39. Polit D, Beck C, Loiselle C, Profetto-McGrath J. Canadian essentials. Philadelphia: Lippincott Williams \& Wilkins; 2007

40. McFarlane W, Levin B, Travis L, Lucas F, Lynch S, Verdi M, et al. Clinical and functional outcomes after 2 years in the early detection and intervention for the prevention of psychosis multisite effectiveness trial. Schizophr Bull. 2015; 41(1):30-41. doi:10.1093/schbul/sbu108.

41. McGarvey E, Leon-Verdin M, Bloomfield K, Wood S, Winters E, Smith J. Effectiveness of A-CRA/ACC in treatment adolescents with cannabis-use disorders. Community Ment Health J. 2014;50(2):150-7. doi:10.1007/ s10597-012-9566-2.

42. Schley C, Ryall V, Crothers L, Radovini S, Fletcher K, Marriage K, et al. Early intervention with difficult to engage, "high-risk" youth: evaluating an intensive outreach approach in youth mental health. Early Interv Psychiatry. 2008;2(3):195-200. doi:10.1111/j.1751-7893.2008.00079.x.

43. Urben S, Mantzouranis G, Baier V, Halfon O, Vallard E, Holzer L. Timing of clinical improvement in assertive community treatment for adolescents: a pilot naturalistic observational study. Arch Psychiatr Nurs. 2016;30(5):645-6. doi:10.1016/j.apnu.2016.04.015.

44. Trusty J, Thompson B, Pretocelli J. Practical guide for reporting effect size in quantitative research in the journal of counseling \& development. J Couns Dev. 2004;82:107-10.

45. GRADE Working Group. Grading. Quality of evidence and strength of recommendations. Brit Med J. 2004;328:1490-4.

46. Adrian N, Smith J. Occupied bed days a redundent currency? An evaluation of the first 10 years of an integrated model of care for mentally ill adolescents. Clin Child Psychol Psychiatry. 2015;20(3):458-71. doi:10.1177/1359104514527298.

47. Ahrens C, Frey J, Knoedler W, Senn-Burke S. Effect of PACT on inpatient psychiatric treatment for adolescents with severe mental illness: a preliminary analysis. Psychiatr Serv. 2007;58:1486-8.

48. Chai A, Assan B, Finch E, Stargatt R, Burchell $P$, Jones $H$, et al. Innovations in practice: effectiveness of specialist adolescent outreach service for at-risk adolescents. J Child Adolesc Ment Health. 2013;18(2):116-9. doi:10.1111/j. 1475-3588.2012.00654.x.

49. Godley M, Godley S, Dennis M, Funk R, Passetti L. Preliminary outcomes from the assertive continuing care experiment for adolescents discharged from residential treatment. J Subst Abus Treat. 2002;23(1):21-32. doi:10. 1016/S0740-5472(02)00230-1. 
50. Godley M, Godley S, Dennis M, Funk R, Passetti L. The effect of assertive continuing care on continuing care linkage, adherence and abstinence following residential treatment for adolescents with substance use disorders. Addiction. 2006;102(1):81-93. doi:10.1111/j.1360-0443.2006.01648.x.

51. Godley S, Garner B, Passetti L, Funk R, Dennis M, Godley M. Adolescent outpatient treatment and continuing care: main findings form a randomized clinical trial. Drug Alcohol Depend. 2010;110(1-2):44-54. doi:10.1016/j.durgsalcdep.2010.02.003.

52. Godley M, Godley S, Dennis M, Funk R, Pasetti L, Petry N. A randomized trial of assertive continuing care and contingency management for adolescents with substance use disorders. J Consult Clin Psychol. 2015;82(1):40-51. doi:10.1007/s10597-015-9984-z.

53. Guy W. The clinical global Impession scale, 1976.

54. Brann P, Coleman G, Luk E. Routine outcome measurement in a child and adolescent mental health service: an evaluation of HoNOSCA. The health of the nation outcome scales for children and adolescents. Aust N Z J Psychiatry. 2001;35(3):370-6. doi:10.1046/j.1440-1614.2001.00890.x

55. Gowers S, Harrington R, Whitton A, Beevor A, Lellitiot P, Wing J. Brief scale for measuring the outcomes of emotional and behavioural disorders in children. Health of the nation outcome scales for children and adolescents (HoNOSCA). Br J Psychiatry. 1999;174(5):413-6. doi:10. 1192/bjp.174.5.413.

56. Dennis M, Titus J, White M, Unsicker J, Hodgkinds D. Global appraisal of individual needs (GAIN): administration guide for the GAIN and related measures. Version 5. Normal: Chestnut Health Systems; 2003. http://www.gaincc.org/psychometricspublications/gain-publications/. Accessed 14 Dec 2016

57. McGlashan T, Miller T, Woods S, Rosen J, Hoffman R, Davidson L. Structured interview for prodromal syndromes. Schizophr Bull. 2003;4(29):703-15.

58. Robinson SM, Sobell MB, Leo Gl. Reliability of the timeline followback for cocaine, cannabis, and cigarette use. Psychol Addict Behav. 2014;28(1):15462. doi:10.1037/a0030992.

59. Flakierska N, Lindstrøm M, Gillberg C. Schoolrefusal: a 15-20 year follow-up study of 35 Swedish urban children. Br J Psychiatry. 1988;152:834-7. doi:10. 1192/bjp.152.6.834

60. Jones S, Thornicroft G, Coffey M, Dunn G. A brief mental health outcome scale-reliability and validity of the global assessments of functioning (GAF). Brit J Psychiatry. 1995;166:654-9. doi:10.1192/bjp.166.5.654.

61. Schaffer D, Gloud M, Brasic J, Ambrosini P, Fisher P, Bird H, et al. A Children's global assessment Scall (CGAS). Arch Gen Psychiatry. 1983;40(11): 1228-31. doi:10.1001/archpsyc.1983.01790100074010.

62. National Institute for Health and Care Excellence. Depression in children and young people. http://www.nice.org.uk/guidance/qs48. Accessed 29 Nov 2016.

63. Mendenhall A, Demeter C, Findling R, Frazier T, Fristad M, Youngstrom E, et al. Factors influencing mental health services utilization by children with serious emotional and behavioral disturbance: results from the LAMS study. Psychiatr Serv. 2011;62(6):650-8.

64. Yearwood EL. Efforts to meet the health care needs of children and adolescents. J Child Adolesc Psychiatr Nurs. 2012;25(1):51-2. doi:10.1111/j. 1744-6171.2011.00314.x.

65. Henggeler SW, Schaeffer CM. Multisystemic therapy ${ }^{\oplus}$ : clinical overview, outcomes, and implication research. Fam Process. 2016;55(3):514-28. doi:10.1111/famp.12232.

66. van der Stouwe T, Asscher J, Stams G, Deković M, van der Laan P. The effectiveness of multisystemic therapy (MST): a meta analysis. Clin Psychol Rev. 2014;34(6):468-81. doi:10.1016/j.cpr.2014.06.006.

67. Wevodau AL. A meta-analytic review of multidimensional family therapy (MDFT) treatment outcomes in 11 randomized controlled trials. Houston: Sam Houston State University; 2012.

68. National Institue for Health and Care Excellence. Antisocial behaviour and conduct disorders in children and young people: recognition and management. 2013. http://www.nice.org.uk/guidance. Accessed 18 Oct 2016

69. Prabhu A, Pandit L, Vardhan G. Pathways to tertiary care adopted by individuals with psychiatric illness. Asian J Psychatr. 2015;16:32-5.

70. Gochman P, Miller R, Rapoport J. Childhood-onset schizophrenia: the challenge of diagnosis. Curr Psychiatry Rep. 2011;13(5):321-2. doi:10.1007/s11920-011-0212-4.

71. Sharfstein S, Dickerson F, Oldham J. The textbook of hospital psychiatry. Washington DC: American Psychiatric Publishing; 2009.

72. Early Psychosis Guidelines Writing Group. Australian clinical guidelines for early psychosis. In: A brief summary for practitioners. Australia. 2nd ed. Melbourne: Orygen Youth; 2007. Health, https:// www.ranzcp.org.
73. National Institute for Health and Care Excellence. Drug misuse in over 16s: psychosocial interventions. 2007. http://www.nta.nhs.uk/uploads/clinical_ guidelines_2007.pdf. Accessed 20 Oct 2016.

74. Tielemans L, Middendorp C, Brook F, de Jong C. Literatuurstudie naar de effectiviteit van casemanagement bij verslaafde patienten. Nijmegen, NISPA/ VNN; 2007.

75. Trimbos Instituut. Multidisciplinaire richtlijn Alcohol. 2008. http://www. ggzrichtlijnen.nl. Accessed 30 Oct 2016.

76. National Institute of Health and Care Excellence. Alcohol-use disorders: diagnosis, assessment and management of harmful drinking and alcohol dependence. 2011. http://www.nice.org.uk/guidance/cg115/chapter/1recommendations\#interventions-for-alcohol-misuse. Accessed 30 Oct 2016.

77. Farrington D. Later life outcomes of truants in the Cambridge study. In: Berg I, Nursen J, editors. Unwillingly to school. London: Gaskell; 1996. p. 96-116.

78. Steiner M, Wagner E. Dropoutstrategie. Grundlage zur Prävetion und Reïngetration von Dropouts in Ausbildung und Beschläftigung. Institut für höhere studien: Wien; 2007.

79. Geller B, Tillman R, Bolhofner K, Zimerman B. Child bipolar I disorder: prospective continuity with adult bipolar I disorder; characteristics of second and third episodes; predictors of 8 year outcome. Arch Gen Psychiatry. 2008;65(10):1125-33. doi:10.1001/archpsyc.65.10.1125.

80. Coldwell CM, Bender WS. The effectiveness of assertive community treatment for homeless populations with severe mental illness: a metaanalysis. Am J Psychiatry. 2007;164(3):393-9. doi:10.1176/ajp.2007.164.3.393.

81. Furr-Holden C, Anthony J. Epidemiological differences in drug dependence. A US-UK cross-national comparison. J Soc Psychiatry Psychiatr Epidemiol. 2003;38:165-72. doi:10.1007/s00127-003-0614-7.

82. Costello EJ, Foley D, Angold A. 10-year research update review: the epidemiology of child and adolescent psychiatric disorders: II. Developmental epidemiology. J Am Acad of Child Adolesc Psychiatry. 2006; 44(10):972-86. doi:10.1097/01.chi.0000184929.41423.c0.

83. International Organization for Standardization. Codes for representation names of countries and subdivisions Part 1. http://www.iso.org/home.html. Accessed 18 Nov 2016.

\section{Submit your next manuscript to BioMed Central and we will help you at every step:}

- We accept pre-submission inquiries

- Our selector tool helps you to find the most relevant journal

- We provide round the clock customer support

- Convenient online submission

- Thorough peer review

- Inclusion in PubMed and all major indexing services

- Maximum visibility for your research

Submit your manuscript at www.biomedcentral.com/submit
Biomed Central 